\title{
The effect of EPA and DHA on metabolic syndrome patients: a systematic review of randomised controlled trials
}

\author{
Eduardo Lopez-Huertas* \\ Estación Experimental Zaidin, Consejo Superior de Investigaciones Científicas (CSIC), \\ Spanish Ministry of Economic Affairs and Competitiveness. Profesor Albareda 1, Granada 18008, Spain
}

\begin{abstract}
Metabolic syndrome (MS) is characterised by accumulation of CVD risk factors. The use of very long chain $n$ - 3 polyunsaturated fatty acids (VLC $n 3$ PUFA) could potentially benefit MS by reducing risk factors. To better understand the possible VLC $n 3$ PUFA benefits, the literature was systematically reviewed for randomised controlled trials (RCT) that published effects of VLC $n 3$ PUFA on MS patients. 17 RCT fulfilled the inclusion criteria and were analysed for relevance to the research question. The available RCT convincingly show that the administration of VLC $n 3$ PUFA doses $>1 \mathrm{~g}$ for at least 3 months produces a significant reduction of triglycerides ranging from $7 \%$ to $25 \%$. These results confirm the hypotriglyceridemic effect of VLC $n 3$ PUFA in MS patients. The triglyceride lowering may produce further benefits by reducing the \% of pro-atherogenic small dense LDL particles (sdLDL) and also perhaps by ameliorating the inflammatory process associated with MS. High doses of VLC $n 3$ PUFA ( $\geq 3 \mathrm{~g}$ /day) may produce further TAG reductions but could raise other risk factors such as LDL-C. No clear effects were found on other MS markers. The combination of VLC $n 3$ PUFA plus a statin may be useful to prevent the occurrence of coronary events. More studies are needed using different amounts of VLC $n 3$ PUFA, time lengths, dietary backgrounds and different profiles of MS patients before clear recommendations can be made.
\end{abstract}

Key words: systematic review: metabolic syndrome: very long chain $n 3$ fatty acids: cardiovascular disease

\section{Introduction}

Metabolic syndrome (MS), also named syndrome X or metabolic syndrome $\mathrm{X}$, is defined by the National Cholesterol Education Program-Adult Treatment Panel III as the presence of at least 3 cardiovascular disease (CVD) risk factors from a list of the following 5: abdominal obesity (waist circumference $>102 \mathrm{~cm}$ for males or $>88 \mathrm{~cm}$ for females), impaired fasting glucose $(\geq 6.1 \mathrm{mmol} / \mathrm{L}$ ), elevated fasting triacylglycerides (TAG $\geq 1.7 \mathrm{mmol} / \mathrm{L}$ ), decreased high-density lipoprotein cholesterol (HDL-C, $<1 \mathrm{mmol} / 1$ for males and $<1.3 \mathrm{mmol} / \mathrm{L}$ for females), and high blood pressure (BP $\geq 130 / 85 \mathrm{~mm} \mathrm{Hg})^{(1)}$. Over the last two decades, the number of people with MS has increased considerably. This increase is directly associated with the global epidemic of obesity and diabetes ${ }^{(2)}$. MS affects approximately $10-25 \%$ of adults worldwide, in some countries and age groups the percentage can be as high as $50-60 \%{ }^{(3)}$. MS increases the risk of suffering from type 2 diabetes and CVD by 5 - and 2 -fold, respectively ${ }^{(4)}$. There is a wealth of evidence from epidemiologic and clinical studies suggesting that modifications in dietary fat composition affect the risk of CVD. Although diet is not specifically identified as a risk factor for MS, there is good evidence to suggest that hypercalorichyperlipidic diets, particularly rich in SFA promote obesity, insulin resistance and $\mathrm{MS}^{(5-7)}$. Very long chain $n-3$ polyunsaturated fatty acids (VLC $n 3$ PUFA) in the diet (namely EPA and DHA) have a positive effect on blood lipid levels. The pleiotropic, cardioprotective effects VLC $n 3$ PUFA have been extensively reported. They specifically reduce plasma TAG levels and thereby the risk of CVD. Other potential mechanisms of cardiovascular protection may include lowering of BP, reduced thrombotic tendency, antiinflammatory and antiarrhythmic effects, improved vascular endothelial function, increased plaque stability, increased paraoxonase levels and improved insulin sensitivity ${ }^{(8)}$.

Abbreviations: AHA, American Heart Association; BP, blood pressure; CAD, coronary artery disease; CAVI, cardio-ankle vascular index; CETP, cholesteryl ester transfer protein; CRP, C-reactive protein; CV, cardiovascular; EFSA, European Food Safety Agency; FA, fatty acids; HDL-C, high-density lipoprotein cholesterol; HMUFA, high monounsaturated fatty acids; HOSO, high oleic sunflower oil; HSFA, high saturated fatty acids; Hsp27, heat shock protein 27; IMA, Ischemia Modified Albumin; VLC n3 PUFA, very long chain $n$-3 polyunsaturated fatty acids; LDL-C, low-density lipoprotein cholesterol; LFHCC, low fat high complex carbohydrate; LFHCC $n 3$, low fat high complex carbohydrate supplemented with VLC $n 3$ PUFA; MS, metabolic syndrome; PAI- 1 , plasminogen activator inhibitor-1; PWV, pulse wave velocity; TC, total cholesterol; t-PA, tissue plasminogen activator; TRL, triacylglycerol rich lipoproteins; RCT, Randomized Controlled Trial; SAA-LDL, Serum Amyloid A-LDL; sdLDL, small dense LDL.

*Corresponding author: E. Lopez-Huertas, fax +34958 129600, email eduardo.lopezhuertas@eez.csic.es 
As a consequence, health authorities and scientific associations have made recommendations of VLC $n 3$ PUFA intake, like the European Food Safety Authority (EFSA) that recommends $250 \mathrm{mg} /$ day $^{(9)}$ for the general population. Only recently, WHO has established new intake recommendations for adults of $250 \mathrm{mg}$ of EPA + DHA per day and $300 \mathrm{mg}$ of $\mathrm{EPA}+\mathrm{DHA}$ for pregnant or lactating women (of which 200 mg should be DHA ${ }^{(10)}$. For hypertriglyceridemic subjects, the American Heart Association (AHA) recommends: 2-4g $\mathrm{EPA}+\mathrm{DHA} / \mathrm{day}^{(11)}$, and for patients with CVD, the AHA recommends $1 \mathrm{~g} /$ day $^{(11)}$ to maintain cardiac function, reduce TAG levels and the risk of CHD.

Therapeutic lifestyle modification to manage risk factors is the first-line therapy for MS patients who are not at high risk of suffering a CVD event ${ }^{(3)}$. However, from a clinical perspective, it is difficult to define the optimum diet with which to treat MS. The use of VLC $n 3$ PUFA could potentially benefit MS by reducing risk factors. However, not many studies have investigated the effects of EPA + DHA in this type of patients and there are no recommendations available. To better understand the possible VLC $n 3$ PUFA benefits, the literature was systematically reviewed for randomised controlled trials (RCT) that published effects of VLC $n 3$ PUFA in MS patients.

\section{Materials and Methods}

\section{Literature search}

The research question applied to the systematic review was "what are the effects of VLC n3 PUFA in MS patients?". The VLC $n 3$ PUFA of particular interest with respect to MS included EPA and DHA from fish oils or their purified forms. The review included English, Spanish, French, Italian, Portuguese and German articles, without limits on time frame or country, published before April 2011. We searched for publications using the electronic databases MEDLINE and ISI Web of Science. The MeSH terms used in the general search and the search strings used were "metabolic syndrome X" AND "metabolic syndrome" AND "fatty acids, omega-3" NOT "alpha-linolenic acid". The search was then limited to "RCT" and "humans" only.

\section{Elegibility criteria}

To qualify, RCT could only include subjects diagnosed with MS who had three, four or five characteristics of the MS, without history of CVD. RCT reporting chronic effects of EPA + DHA (as either supplements or dietary components) and postprandial studies were considered. The studies had to quantify the EPA + DHA supplementation. Studies reporting effects of alpha-linolenic acid in MS patients were excluded. Also, in vitro, animal studies and non-RCT were excluded. 138 articles were firstly identified in the search, 92 original articles, 26 reviews, 12 proceedings papers, 7 meeting abstracts and 1 editorial material. When we limited for RCT and humans (as mentioned above), the number of publications was reduced to 14 . The titles and abstracts were analysed by 2 independent scientists of the field. Three studies were excluded as they did not meet the search criteria: an animal study ${ }^{(12)}$, a RCT using alpha-linolenic acid as omega 3 source instead of $\mathrm{EPA}+\mathrm{DHA}^{(13)}$, and a study describing and evaluating a food-exchange model in MS patients for further research trials ${ }^{(14)}$. The 11 remaining trials were relevant to the research question and were included ${ }^{(15-25)}$. The references sections of those 11 studies revealed 6 additional RCT with MS patients that met the search criteria, and were also included $^{(26-31)}$.

\section{Quality and applicability assessment}

All RCT were assessed for both study quality and applicability (Tables 1 and 2). Methodological quality refers to the design, conduct, and reporting of the clinical study. Because studies with a variety of design types were evaluated, a 3-level classification of study quality was used ${ }^{(32)}$, as follows: A) least bias, when the study mostly adhered to the commonly held concepts of good quality, including formal randomized study, clear description of the population, setting, interventions and comparison groups, appropriate measurement of outcomes, appropriate statistical and analytic methods and reporting, no reporting errors, $<20 \%$ dropout, clear reporting of dropouts, and no obvious bias. B) Susceptible to some bias. The study had some deficiencies but none likely to cause major bias or may be missing information making assessment of the limitations and potential problems difficult. C) significant bias. Study has serious errors in design, analysis, or reporting or may have large amount of missing information or discrepancies in reporting. Regarding applicability, a 3-level classification was also used. I: if the sample was representative of the target population sufficiently large to cover both sexes, a wide age range, and where dietary intake was controlled. II: if the sample was representative of a relevant sub-group of the target population and food intake was not controlled but the subjects received dietary advice; III: if sample was representative of a narrow subgroup of subjects only, not well applicable to other subgroups and/or where dietary intake was not controlled at all.

\section{Results}

The studies that fulfilled the inclusion criteria and were analysed for relevance to the research question were 17 in total ${ }^{(15-31)}$. Information on each study is summarised in Tables 1 and 2 . Twelve publications showed results from European countries (Spain, Norway, Ireland, France, Poland, The Nederlands, Sweden, Denmark, United Kingdom), two from Canada, three from Japan, one from Brazil and one from Iran. Seven European publications were results of the LIPGENE project, a large scale European Union Project conducted by 25 research centres across Europe focused on diet, genomics and the MS (http:// www.ucd.ie/lipgene/). The number of participants varied from $8^{(19,21)}$ to $957^{(17)}$ in the selected studies. Eleven studies reported chronic effects of VLC $n 3$ PUFA by administering $n 3$ rich diets or supplements for a period of time and analysed parameters of MS patients in fasting conditions, compared with controls (Table 1). Six RCT published recently have evaluated the postprandial response of MS patients to fat 
Table 1. RCT describing chronic effects produced by the supplementation with EPA + DHA in MS patients ${ }^{(1)}$

\begin{tabular}{|c|c|c|c|c|c|c|c|}
\hline $\begin{array}{l}\text { Author, year } \\
\text { (reference } \\
\text { number) }\end{array}$ & $n$ & $\begin{array}{l}\text { Dose } \\
\text { (g/day) }\end{array}$ & Duration & Quality $^{(2)}$ & $\begin{array}{l}\text { Applica } \\
\text {-bility }\end{array}$ & Changes observed in the VLC n3 PUFA Group & Conclusion of the study \\
\hline $\begin{array}{l}\text { Brady et al., } \\
\quad 2004^{(15)}\end{array}$ & 30 & $2 \cdot 5$ & 6 weeks & B & III & $\begin{array}{l}\text { TAG }-25 \% \text {, small dense LDL }-11 \% \text { Greater TAG reductions } \\
\text { in this group }\end{array}$ & $\begin{array}{l}\text { Cardioprotective TAG lowering effects of the EPA + DHA } \\
\text { supplement not interfered by the high } n-6 \text { PUFA diet }\end{array}$ \\
\hline $\begin{array}{l}\text { Benito et al. } \\
2006^{(16)}\end{array}$ & 72 & $0 \cdot 186$ & 3 months & A & II & $\begin{array}{l}\text { Systolic BP }-9.7 \mathrm{~mm} \mathrm{Hg} \text {, diastolic BP }-7.3 \mathrm{~mm} \mathrm{Hg} \text {, TC }-6.2 \% \text {, } \\
\text { LDL-C }-7.5 \% \text {, TAG }-13.3 \% \text {, fasting glucose }-5,3 \%\end{array}$ & $\begin{array}{l}\text { Low dose of EPA + DHA administered with oleic acid in a } \\
\text { dairy drink improved the CV risk profile in MS patients }\end{array}$ \\
\hline $\begin{array}{l}\text { Satoh et al., } \\
\quad 2007^{(26)}\end{array}$ & 44 & $1 \cdot 8$ & 3 months & B & II & $\begin{array}{l}\text { CRP }-63 \% \text {, TAG of remnant lipoprotein particles }-40 \% \text {, } \\
\text { cholesteryl ester transfer protein activity }-2.5 \% \text {, sdLDL } \\
\text { particles }-1.3 \%\end{array}$ & $\begin{array}{l}\text { The biomarkers modified by the EPA supplementation } \\
\text { potentially reduce development of atherosclerosis and } \\
\text { CVD in MS }\end{array}$ \\
\hline $\begin{array}{l}\text { Saito et al., } \\
2008^{(17)}\end{array}$ & 957 & $1 \cdot 8$ & 5 years & A & 1 & TAG $-23 \%$. Risk for major coronary events $-53 \%$ vs control & $\begin{array}{l}\text { EPA may be especially beneficial in patients who with } \\
\text { abnormal TAG and HDL-C levels }\end{array}$ \\
\hline $\begin{array}{l}\text { Ebrahimi etal., } \\
2009^{(18)}\end{array}$ & 89 & 0.3 & 6 months & B & II & $\begin{array}{l}\text { Weight }-3.8 \% \text {, systolic BP }-5 \% \text {, TC }-13 \% \text {, LDL-C }-21 \% \text {, } \\
\text { TAG }-18 \% \text {, CRP }-66 \% \text { and Hsp27 }-68 \%\end{array}$ & $\begin{array}{l}\text { The low dose of VLC-omega } 3 \text { PUFA could be useful to } \\
\text { improve the CV risk profile of the MS patients, but to be } \\
\text { confirmed }\end{array}$ \\
\hline $\begin{array}{l}\text { Satoh et al., } \\
\quad 2009^{(20)}\end{array}$ & 92 & 1.8 & 3 months & A & 1 & $\begin{array}{l}\text { TAG }-25 \% \text {, SAA-LDL }-17 \% \text {, CRP }-26 \% \text {, PWV }-5,6 \% \text {, CAVI } \\
-3.5 \% \text {, adiponectin }+8 \% \text {. }\end{array}$ & $\begin{array}{l}\text { EPA improves arterial stiffness through supression of } \\
\text { SAA-LDL, which could be an important step for the EPA } \\
\text { anti-atherogenic effects }\end{array}$ \\
\hline $\begin{array}{l}\text { Hartwich et al., } \\
2009^{(22)}\end{array}$ & 78 & $1 \cdot 24$ & 12 weeks & A & I & $\begin{array}{l}\text { Favourably altered LDL phenotype from } B \text { (sdLDL) to } A \text {, } \\
\text { decreased density of LDL, no changed in oxidative stress } \\
\text { markers }\end{array}$ & $\begin{array}{l}\text { The study showed efficacy of dietary } n-3 \text { PUFA to modify } \\
\text { pro-atherogenic to less atherogenic LDL phenotype in MS } \\
\text { patients. }\end{array}$ \\
\hline $\begin{array}{l}\text { Gulseth et al., } \\
2010^{(24)}\end{array}$ & 391 & $1 \cdot 24$ & 12 weeks & A & I & No changes in systolic BP, diastolic BP or pulse pressure & Lack of effect in BP. n3 supplement dose may be too low \\
\hline $\begin{array}{l}\text { Tierney et al., } \\
2010^{(27)}\end{array}$ & 317 & $1 \cdot 24$ & 12 weeks & A & 1 & $\begin{array}{l}\text { no effect in insulin sensitivity, TC, LDL-C, BP or } \\
\text { inflammation. TAG }-7 \% \text {, NEFA - } 10 \% \text {, TC:HDL-C }-4 \% \text {, } \\
\text { atherogenic index }-19 \% \text {, ApoCIII -3,6\% }\end{array}$ & $\begin{array}{l}\text { The VLC } n-3 \text { PUFA diet improved TAG-related MS risk } \\
\text { profiles }\end{array}$ \\
\hline $\begin{array}{l}\text { Petersson } \\
\text { et al., } \\
2010^{(17)}\end{array}$ & 317 & $1 \cdot 24$ & 12 weeks & A & I & $\begin{array}{l}\text { No effects of oxidative stress and inflammation markers } \\
\text { (8-iso-PGF2 } \alpha, 15 \text {-keto-13,14-dihydro-PGF22 } \alpha, \text { CRP) }\end{array}$ & $\begin{array}{l}\text { Lack of effect explained by the low } n 3 \text { dose administered } \\
\text { or high } n 3 \text { endogenous levels at baseline }\end{array}$ \\
\hline $\begin{array}{l}\text { Simão et al., } \\
2010^{(25)}\end{array}$ & 40 & 3 & 90 days & B & II & $\begin{array}{l}\text { TAG }-23 \% \text {, TC }+7 \cdot 9 \% \text {, LDL-C }+18 \cdot 8 \% \text { Plasma Antioxidant } \\
\text { capacity }+16 \% \text {, blood glucose }+4 \% \text {, insulin resistance } \\
\text { index }+24 \%\end{array}$ & $\begin{array}{l}\text { The intake of fish oil favourably reduced TAG and } \\
\text { increased antioxidant capacity but increased TC, LDL-C } \\
\text { and insulin resistance }\end{array}$ \\
\hline
\end{tabular}

(1) Abbreviations: Atherogenic index, log (TAG/HDL-C); BP, blood pressure; CAVI, cardio-ankle vascular index; CETP, cholesteryl ester transfer protein; CRP, C-reactive protein; CV, cardiovascular; HDL-C, high-density lipoprotein cholesterol; Hsp27, heat shock protein 27; VLC n3 PUFA, long chain $n$-3 polyunsaturated fatty acids; LDL-C, low-density lipoprotein cholesterol; MS, metabolic syndrome; n, number of subjects in the study; NEFA, non-esterified 作

(2) The criteria used to assess quality and applicability of the studies in the Materials and Methods section. 
Table 2. RCT describing postprandial effects produced by the supplementation with EPA + DHA in MS patients ${ }^{(1)}$

\begin{tabular}{|c|c|c|c|c|c|c|}
\hline $\begin{array}{l}\text { First } \\
\text { author/year } \\
\text { (reference) }\end{array}$ & $n$ & $\begin{array}{l}\text { VLC } n 3 \text { PUFA } \\
\text { dose in post } \\
\text { prandial test }(\mathrm{g})\end{array}$ & Quality $^{(2)}$ & $\begin{array}{l}\text { Applica } \\
\text {-bility }\end{array}$ & Changes observed in the n 3 Group & Conclusion of the study \\
\hline $\begin{array}{l}\text { Tulk and } \\
\text { Robinson, } \\
2009^{(19)}\end{array}$ & 8 & $3 \cdot 3$ & A & II & $\begin{array}{l}\text { No changes in postprandial TAG or } \\
\text { inflammatory response (IL-6, } \\
\text { soluble IL-6 receptor and CRP) }\end{array}$ & $\begin{array}{l}\text { Increasing the } n-3 \text { PUFA content } \\
\text { of a HSFA had no effects on } \\
\text { postprandial TAG or inflammatory } \\
\text { responses }\end{array}$ \\
\hline $\begin{array}{l}\text { Montegaard } \\
\text { et al., } \\
2009^{(21)}\end{array}$ & 8 & $3 \cdot 3$ & A & II & $\begin{array}{l}\text { Reduction of PAl-1 concentration } \\
\text { and activity reductions of t-PA } \\
\text { activity. No effects on t-PA } \\
\text { concentration and platelet } \\
\text { aggregation. }\end{array}$ & $\begin{array}{l}\text { In the context of a HSFA intake, a } \\
\text { lower capacity for fibrinolysis was } \\
\text { produced by the high } n-3 \text { fat load }\end{array}$ \\
\hline $\begin{array}{l}\text { Jiménez- } \\
\text { Gómez } \\
\text { et al., } \\
2010^{(23)}\end{array}$ & 117 & $1 \cdot 24$ & A & 1 & $\begin{array}{l}\text { Lower postprandial TAG concen- } \\
\text { tration and TRL metabolism }\end{array}$ & $\begin{array}{l}\text { The adverse postprandial TAG- } \\
\text { raising effects of long-term low } \\
\text { fat high complex carbohydrate } \\
\text { diets may be avoided by co- } \\
\text { administration of VLC n3 PUFA }\end{array}$ \\
\hline $\begin{array}{l}\text { Perez- } \\
\text { Martínez } \\
\text { et al., } \\
2010^{(29)}\end{array}$ & 74 & $1 \cdot 24$ & A & 1 & No effects & $\begin{array}{l}\text { Postprandial state is important for } \\
\text { understanding possible cardio- } \\
\text { protective effects associated with } \\
\text { the Mediterranean diet in MS } \\
\text { patients }\end{array}$ \\
\hline $\begin{array}{l}\text { Hartwich } \\
\text { et al., } \\
2010^{(31)}\end{array}$ & 164 & $1 \cdot 24$ & A & 1 & $\begin{array}{l}\text { Reduced postprandial LDL-C and } \\
\text { minimalised the increase of IMA }\end{array}$ & $\begin{array}{l}\text { The VLC } n \text {-3 PUFA meal could } \\
\text { attenuate the adverse effect } \\
\text { of the other test meals on LDL } \\
\text { particle profile and Ischemia } \\
\text { Modified Albumin }\end{array}$ \\
\hline $\begin{array}{l}\text { van Hees } \\
\text { et al., } \\
2010^{(30)}\end{array}$ & 29 & $1 \cdot 24$ & A & II & $\begin{array}{l}\text { No effects on forearm muscle FA } \\
\text { handling, decrease postprandial } \\
\text { TAG concentrations }\end{array}$ & $\begin{array}{l}\text { Chronic manipulation of dietary fat } \\
\text { quantity and quality did not affect } \\
\text { forearm muscle FA handling in } \\
\text { men with MS }\end{array}$ \\
\hline
\end{tabular}

(1) Abbreviations: AUC, area under the curve; CRP, C-reactive protein; IMA, Ischemia Modified Albumin; VLC n3 PUFA, long chain $n$-3 polyunsaturated fatty acids; LDL-C, low-density lipoprotein cholesterol; MS, metabolic syndrome; PAI-1, plasminogen activator inhibitor-1; SFA, saturated fatty acids; sICAM-1 soluble form of intercellular cell adhesion molecule-1; t-PA, tissue plasminogen activator; TRL, triacylglycerol rich lipoproteins; RCT, Randomized Controlled Trial.

(2) The criteria used to assess quality and applicability of the studies in the Materials and Methods section.

loads enriched with VLC omega 3 PUFA $^{(19,21,23,29-31)}$, the most recent ones are results from the LIPGENE project (Table 2). The results of the trials analysing chronic effects and biomarkers in fasting conditions are presented first.

\section{Studies reporting chronic effects of VLC-n3 PUFA}

The first RCT in MS patients reporting effects of VLC n3 PUFA was published in 2004 by Brady et al. This study examined whether a higher intake of $n-6$ PUFA in combination with a low intake of VLC $n 3$ PUFA played a role in markers of MS in Indian Asians ${ }^{(15)}$. The results demonstrated that supplementation with VLC $n 3$ PUFA had no impact on insulin action but showed significant reductions in fasting TAG and a reduction in the percentage of denser, proatherogenic LDL particles. Another RCT with MS patients investigated the effects of an $\mathrm{EPA}+\mathrm{DHA}$ and oleic acid enriched milk compared with a control milk ${ }^{(16)}$. At the end of the 3-month study, MS patients of the enriched milk group improved fasting glucose levels and significantly reduced BP, TAG, total and LDL-cholesterol ${ }^{(33)}$. In a study carried out in Japan ${ }^{(26)}$, the supplementation with 1.8 of EPA for 3 months showed reductions in the TAG of the remnant lipoprotein particles, cholesteryl ester transfer protein (CETP) activity (that may reduce the atherogenic process ${ }^{34}$ ), the proportion of small dense LDL particles (sdLDL) and C-reactive protein (CRP). The JELIS study was a large-scale clinical trial examining the effects of EPA on coronary artery disease
(CAD) $(n=14,981)^{(17)}$. The patients were assigned to an EPA + statin group, administering $1.8 \mathrm{~g}$ of $\mathrm{EPA} / \mathrm{d}$, or a control group that received only the statin, for a period of 5 years. EPA did not affect TC, LDL-C or HDL-C, but significantly reduced TAG. The EPA treatment lowered the risk for major coronary events of the high-risk group (high TAG/low HDL-C) by $53 \%$ compared with the control, even in a Japanese population with high fish intake ${ }^{(35)}(100 \mathrm{~g} /$ day on average or $0 \cdot 1-2 \mathrm{~g} /$ day of $\mathrm{EPA}+$ DHA depending on the fish source).

Ebrahimi et al. ${ }^{(18)}$ investigated the effects produced by the administration of $1 \mathrm{~g}$ of fish oil per day to a group of MS patients. The intervention group significantly reduced weight, systolic BP, TC, LDL-C, TAG, high sensitivity CRP and heat shock protein 27 (Hsp27) antibody titres, a protein associated with CVD risk factors $^{(36)}$, at the end of the 6 months period. A recent RCT investigated the anti-atherogenic mechanisms of EPA in MS patients ${ }^{(20)}$. The EPA treatment ( $1.8 \mathrm{~g} /$ day of purified EPA for 3 month), significantly reduced the levels of TAG, Serum Amyloid A-LDL (SAA-LDL, a novel OxLDL ${ }^{(37)}$ ) and CRP. Adiponectin, an antiinflamatory marker related with $\mathrm{MS}^{(38)}$ increased by $8 \%$. Pulse wave velocity (PWV) and cardio-ankle vascular index (CAVI) that estimate arterial stiffness were also reduced.

Four RCT from the LIPGENE project investigated effects of VLC $n 3$ PUFA on 1) LDL phenotype $\left.\left.{ }^{(22)}, 2\right) \mathrm{BP}^{(24)}, 3\right)$ insulin sensitivity ${ }^{(27)}$, and 4) oxidative stress and inflammatory markers $^{(28)}$. In these four studies, the group of MS patients were divided into 4 study groups (A-D) that received one of the 
following four isocaloric diets (LIPGENE diets): (A) High SFA diet; (B) High MUFA diet; (C) low-fat diet with a daily supplement of $1.24 \mathrm{~g} / \mathrm{d}$ high oleic sunflower oil; and (D): lowfat with a supplement of $1.24 \mathrm{~g} / \mathrm{d}$ VLC $n 3$ PUFA ( $n 3$ diet). The diet and supplements were administered for 12 weeks and the biomarkers were analysed at the beginning and at the end of the study period.

In the first study ${ }^{(22)}$, the $n 3$ diet resulted in favorable alteration of LDL phenotype from small, dense proatherogenic to large LDL particles and also decreased LDL density. In the second study $^{(24)}$, no significant differences on systolic or diastolic BP were found in any of the study groups. The authors discussed that the low dose of omega 3 used in the study $(1.2 \mathrm{~g} /$ day) could have explained the lack of effect as only supplements of high doses $(>3 \mathrm{~g} / \mathrm{d})$ have been reported to lower BP in hypertensive patients ${ }^{(39)}$. In the third study ${ }^{(27)}$, the LIPGENE diets showed no effect in insulin sensitivity, TC, LDL-C, inflammation or BP in the entire cohort. Regarding oxidative stress and inflammation, the results obtained by Peterson et al. ${ }^{(28)}$ showed no effects of the LIPGENE diets on markers of oxidative stress or inflammation. This lack of effects was explained by the low dose of omega 3 compared with previous studies ${ }^{(33)}$ or the endogenous levels of $n 3$ fatty acids at baseline being too high to be modified by the diets administered.

Finally, one study carried out in Brazil ${ }^{(25)}$ investigated the effects produced by the administration of $1.8 \mathrm{~g}$ of EPA $+1.2 \mathrm{~g}$ DHA per day ( $10 \mathrm{~g}$ of fish oil) to a group of MS patients. The fish oil group decreased TAG but increased total cholesterol, LDL-C and the antioxidant capacity of plasma. In addition, the fish oil group worsened the glucose control in line with other previous studies $^{(40,41)}$.

\section{Postprandial studies with VLC-omega 3 PUFA}

Elevated postprandial lipemia has recently emerged as a risk factor for CVD, indicating that this disease is in part a postprandial fenomenon ${ }^{(42,43)}$. Postprandial hyperlipidemia is characteristic of MS patients, with increased postprandial TAG-rich lipoprotein (TRL) concentrations ${ }^{(44,45)}$.

Tulk and Robinson ${ }^{(19)}$ showed that increasing the VLC $n 3$ PUFA content of a high-SFA oral fat load did not change postprandial TAG or inflammatory responses. Using a similar design, the same research group showed that a high $n 3$ fat load increased PAI-1 reduced t-PA activity compared with the low $n$ - 3 fat load. The authors concluded that in the context of a high SFA intake, a lower capacity for fibrinolysis was produced by the high VLC n3 PUFA fat load.

From the LIPGENE project, four RCT have evaluated postprandial effects of VLC $n 3$ PUFA, all of them using a similar design, as follows. MS patients were divided into 4 groups that received the LIPGENE diets A-D (see above) for 12 weeks. A fat challenge with the same fat composition as the LIPGENE diets, but administering $0.7 \mathrm{~g}$ of fat $\mathrm{load} / \mathrm{kg}$ of body weight, was conducted pre- and postintervention. Jimenez-Gómez et al. ${ }^{(23)}$ examined the postprandial effects of the fat loads in the lipoprotein profile of 117 MS patients. The $n 3$ diet group had a lower postprandial TAG concentration than the other diet groups. In contrast, long-term ingestion of the $n 3$ diet did not have any effect on postprandial TAG and TRL. The same research group reported no effects of the $n 3$ diet on the endothelium-dependent vasomotor function and plasma levels of cellular adhesion molecules in 75 MS patients ${ }^{(29)}$. Another study reported that the $n 3$ diet group could favourably modify the LDL particle profile and plasma Ischemia Modified Albumin (IMA) ${ }^{(31)}$. Finally, the administration of the LIPGENE fat loads did not affect forearm muscle FA handling in men with MS, but the VLC $n 3$ PUFA group decreased their postprandial TAG concentrations ${ }^{(30)}$.

\section{Discussion}

\section{Biomarkers of intake}

The use of biomarkers of intake is essential to show compliance with the intake of the supplement or test food of the study and to correlate effects produced by the dietary fat. However, there is little consensus about which biomarker of dietary fat modification should be used in RCT. Of the studies showing chronic effects of VLC $n 3$ PUFA, only 7 studies reported biomarkers of intake in blood, including plasma concentration of EPA/DHA fatty acids ${ }^{(26-28,17)}$, increases in the $n 3 / n 6$ ratio of plasma $\mathrm{FA}^{(22)}$, percentage of $n 3 \mathrm{FA}$ in serum phospholipids ${ }^{(16)}$ and the ratio of $n 6: n 3$ platelet membrane phospholipids ${ }^{(15)}$. All the VLC $n 3$ PUFA supplements used in the trials were either fish oils high in EPA (as triglycerides) or purified EPA (as ethyl esters) with the exception of one study ${ }^{(16)}$ using DHA-rich oil (from unknown origin). The intervention periods ranged from 6 weeks ${ }^{(16)}$ to 5 years ${ }^{(17)}$ and the amounts of VLC $n-3$ PUFA administered ranged from $186 \mathrm{mg} /$ day $^{(16)}$ to $3 \mathrm{~g} / \mathrm{d}^{(25)}$. The increases in plasma EPA or $n 3 / n 6$ ratio ranged $60 \%-120 \%$ and were reported after at least 6 weeks of intake. The available RCT showed that in order to observe a significant increase in plasma EPA in MS patients, a minimum amount of $1.2 \mathrm{~g}$ or $4 \mathrm{~g}$ of fish oil has to be administered for at least 3 months or 6 weeks, respectively. The study using the low dose $(186 \mathrm{mg} /$ day) of DHA oil for 2 months did not show any significant increase in plasma EPA or DHA. The use of one standardised biomarker of dietary fat modification would be desirable for this type of interventions. In this sense, erythrocyte EPA + DHA could be an option as it has been suggested to be a useful biomarker for CHD that may also predict the risk of cardiac events ${ }^{(46)}$.

\section{Effects of VLC n3 PUFA on MS}

a) VLC n3 PUFA and blood lipids. Elevated fasting TAG increases the risk of $\mathrm{CVD}^{(1)}$. The TAG lowering effects of VLC $n 3$ PUFA have been extensively described ${ }^{(47)}$. High doses $(2-4 \mathrm{~g} / \mathrm{d})$ of $\mathrm{EPA}+\mathrm{DHA}$ decrease serum triglycerides in both normo- and hyperlipidaemic individuals but low doses have also reported reductions when substitute $\mathrm{SFA}^{(48,49)}$. The magnitude of the effects is related both to the dose of $\mathrm{EPA}+\mathrm{DHA}$ and to the baseline concentrations of triglycerides $^{(50)}$. Harris ${ }^{(51)}$ observed a mean reduction of $35 \%$ in subjects with hypertriglyceridaemia and of $24 \%$ in those with serum triglycerides $<2 \mathrm{mmol} / \mathrm{L}$. In the meta-analysis by Balk et al. ${ }^{(32)}$, 
a mean reduction of $27 \%$ in serum triglyceride concentrations was observed. In the diet and lifestyle recommendations given by the AHA, 2-4 g EPA + DHA per day provided in capsules under physician's supervision are recommended for individuals with hyper-triglyceridaemia to lower TAG $20-40 \%{ }^{(11)}$.

All RCT reporting blood lipid effects upon supplementation with VLC $n$-3 PUFA showed fasting TAG reductions, ranging from $7 \%$ to $25 \%$ (Fig. 1). One study also reported $40 \%$ reductions of TAG in remnant lipoprotein particles ${ }^{(26)}$. The mechanisms that explain the TAG lowering effect include inhibition of triglyceride synthesis, stimulation of fatty acid betaoxidation, and increased lipoprotein lipase-mediated clearance of VLDL triglycerides ${ }^{(50)}$. The reported reductions in apo CIII levels ${ }^{(27)}$ would facilitate TRL catabolism and apo-E dependent hepatic uptake of TRL remnants. Increased postprandial lipemia has recently emerged as a CVD risk factor, indicating that this disease is, at least in part, a postprandial phenomenon. Patients with MS usually have increased postprandial lipemia. However, the 5 postprandial studies administering VLC $n 3$ PUFA showed little improvements in the postprandial TAG response. Only one study concluded that the administration of VLC $n$-3 PUFA could reduce the adverse postprandial TAGraising effects of long-term LFHCC diets ${ }^{(23)}$.

None of the considered studies reported modifications of HDL-C by administration of VLC $n 3$ PUFA. One study showed an activity reduction of CETP, but without effect of HDL-C ${ }^{(26)}$. Regarding TC and LDL-C, the RCT supplementing VLC $n 3$ PUFA to MS patients showed conflicting results: an increase in TC and LDL cholesterol was reported when high doses $(3 \mathrm{~g} / \mathrm{d})$ were used for 3 months ${ }^{(25)}$, whilst administration of $1 \mathrm{~g}$ of fish oil containing $300 \mathrm{mg}$ EPA + DHA for 6 months resulted in TC and LDL-C reductions ${ }^{(18)}$. In this latter study, the volunteers were not instructed to maintain their diet and lifestyle, the dietary intake was not controlled and a $3.8 \%$ reduction of body weight was obtained at the end of the study, which could have played a part in the reductions observed. Benito et al. ${ }^{(16)}$ also described reductions in TC and LDL-C upon 3-month consumption of a dairy drink where SFA were substituted by EPA + DHA (186 mg/day) and oleic acid. EPA plus DHA at high doses $(2-4 \mathrm{~g} / \mathrm{d})$ have multiple effects on blood lipids ${ }^{(50)}$. TC and LDL-C concentrations, are generally not affected by this VLC $n 3$ PUFA supplementation, but in subjects with hypertriglyceridaemia, LDL-cholesterol concentrations may be increased by $5-10 \%{ }^{(32,51,52)}$. Whilst the TAG reduction produced by VLC n3 PUFA produces clear CV benefits, the concomitant LDL-C increases reported at moderate to high doses represent a risk to these patients. The daily dose of EPA + DHA and length of time needed to produce a relevant TAG reduction without increasing LDL-C or TC is yet to be determined for MS patients. More studies are required to clarify this point.

b) VLC n3 PUFA and LDL phenotype. LDL particle size is an important predictor of $\mathrm{CV}$ events and progression of $\mathrm{CHD}^{(53,54)}$. The sdLDL pro-atherogenic particles have been associated with obesity, insulin resistance, high blood TAG and oxidative stress ${ }^{(55)}$. Supplementation of MS patients with VLC $n 3$ PUFA consistently reduce the percentage of sdLDL particles in favour of the large, buoyant, less atherogenic LDL phenotype $(15,22,29)$ which potentially reduces the CV risk. sdLDL concentrations are very much influenced by plasma TAG ${ }^{(56)}$. In MS, slow clearance of TAG from TRL lipoproteins allows for longer periods of circulating TAG, which can directly affect the composition of LDL. Increased transfer of TAG to LDL via CETP during neutral-lipid exchange and subsequent hydrolysis of LDL-TAG by lipases results in a preponderance of $\mathrm{sdLDL}^{(56)}$. Suppression of TAG production in the liver by EPA and reduction of CETP activity may explain the beneficial phenotype shift.

c) VLC n-3 PUFA and BP. Data from the available studies indicate that supplementation of MS patients with VLC $n 3$ PUFA does not produce significant effects on $\mathrm{BP}$ with the doses used. The large and well designed trial by Gulseth et $a{ }^{(24)}$ from the LIPGENE project addressed the effects of VLC $n 3$ PUFA on the BP of MS patients. This trial showed no effects on BP of a dose of $1.24 \mathrm{~g}$ /day for three months. In line with this, a trial by Murphy et al. ${ }^{(57)}, 86$ overweight subjects with high serum TAG were randomised to $1 \mathrm{~g}$ /day of $\mathrm{EPA}+\mathrm{DHA}$ (from enriched foods) or placebo, for 6 months, obtained no significant effects on BP. However, other two RCT trials described above ${ }^{(16,18)}$ reported significant decreases

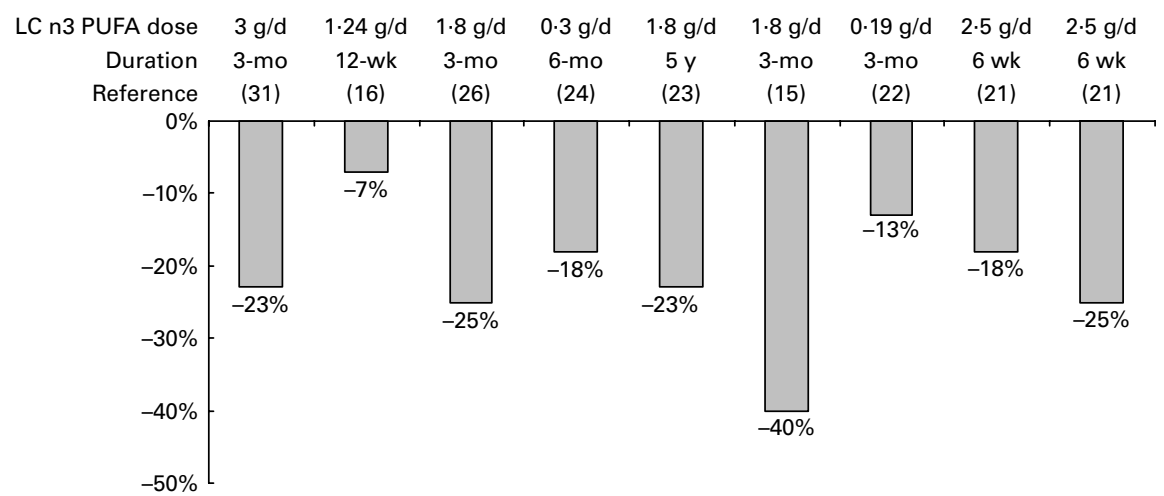

Fig. 1. TAG reductions ${ }^{(1,2)}$ reported in RCT with MS patients upon VLC $n 3$ PUFA supplementation. ${ }^{(1)}$ Expressed as percentages calculated from baseline values. (2) All reductions were statistically significant $(P<0.05)$. 
of BP using much lower amounts (300 $\mathrm{mg}$ and $186 \mathrm{mg} /$ day). In those trials however, the patients from the intervention group lost a significant amount of weight during the study period which may indicate that the BP effect may not be derived from the $n 3$ supplementation.

Indeed, EFSA, after a thorough revision of the scientific evidence, indicated that much higher doses of EPA + DHA $(\geq 3$ grams/day) are needed to have a short-term effect on systolic $\mathrm{BP}$ in subjects with untreated hypertension ${ }^{(52,58)}(\sim 3-5 \mathrm{mmHg}$ decrease in systolic BP), which may also have smaller effects in normotensives $(\sim 1 \mathrm{mmHg}$ decrease in systolic BP). Studies with MS patients using those high doses of EPA + DHA are currently lacking. Interestingly, the recent study by Satoh et al. ${ }^{(20)}$ in MS patients showed that $n 3$ supplementation of $1.8 \mathrm{~g}$ /day for 3 months improved pulse wave velocity and cardio-ankle vascular index, two biomarkers of arterial stiffness, the latter being less influenced by BP changes. Perhaps the use of these new biomarkers would be useful to better characterise the magnitude of the effects. It should be stated here that the above RCT did not differentiate between MS patients with normal or high $\mathrm{BP}$ at baseline, and antihypertensive medication was sometimes allowed $^{(24)}$. These factors make more difficult the interpretation of the data. Whether MS patients, all suffering from high BP as risk factor, may benefit from VLC $n 3$ PUFA supplementation remains unanswered.

d) VLC n-3 PUFA and glucose control. Epidemiologic studies have reported a lower prevalence of impaired glucose tolerance and type-2 diabetes in populations consuming large amounts of fish ${ }^{(59)}$. VLC $n 3$ PUFA may decrease insulin resistance through a number of mechanisms including decrease in circulating TG and small dense LDL particles, increasing membrane fluidity and signal transduction. Further, substituting saturated fat with unsaturated fat, such as $n$-3 PUFAs, may have beneficial effects on insulin sensitivity ${ }^{(60)}$. This change in dietary fat may reduce the risk of progression to type- 2 diabetes from impaired glucose tolerance by improving hemostasis, albuminuria, subclinical inflammation, oxidative stress and slowing progression of artery narrowing ${ }^{(61)}$. Clinical studies have shown that consumption of $n-3$ PUFAs has cardioprotective effects in persons with type- 2 diabetes without adverse effects on glucose control and insulin activity. 3 different meta-analysis concluded that the use of moderate to high amounts of fish oil in diabetics had no effect on glycemic control $^{(32,62,63)}$. More recently published reviews also failed to show effects of VLC $n-3$ PUFA on the glucose control of type-2 diabetes patients ${ }^{(64-66)}$.

In MS patients, effects of fasting glucose, insulin and insulin resistance (shown as HOMA) were reported in 5 RCT using different doses of $n-3$ PUFA. $3 \mathrm{~g}$ /day of EPA + DHA for 3 months increased blood glucose and insulin resistance by $4 \%$ and $24 \%$, respectively ${ }^{(25)}$. Three studies administering daily doses of $2.5 \mathrm{~g}$ for 6 weeks, $1.8 \mathrm{~g}$ and $1.2 \mathrm{~g}$ both for 3 months did not show any effects ${ }^{(15,26,27)}$. No changes in glycosilated haemoglobin were reported ${ }^{(26)}$. The 3-month study with the low dose of EPA + DHA (186 mg/day) administered in a dairy drink showed that fasting glucose was reduced by $5.3 \%$ in the $n 3$ group but the effect of the oleic acid and the weight reduction observed cannot be ruled out. Therefore, there is no evidence of beneficial effects of VLC $n 3$ PUFA on the blood glucose control of MS patients and may even be harmful at high doses. Future studies with different $\mathrm{EPA}+\mathrm{DHA}$ doses are needed to determine if increased consumption of $n-3$ PUFA will delay the conversion of insulinresistant subjects (MS) to diabetics.

e) VLC n-3 PUFA and inflammation. Several features of MS are associated with increased inflammatory and oxidative stress markers ${ }^{(67-69)}$. For example, MS patients usually have high CRP as a manifestation of proinflammatory status. In theory, supplementation with EPA + DHA should originate production of less-potent eicosanoids with anti-inflammatory and antithrombotic effects (compared with the $n 6$ araquidonic acid) but the reports available are controversial. The LIPGENE intervention studies showed no significant effect of dietary fat modification (quantity and quality) and VLC $n 3$ PUFA on several markers of inflammation (CRP, 15-keto-13,14-dihydro$\mathrm{PGF}_{2 \alpha}$, IL-6, TNFalpha, sICAM, sVCAM, resistin, adiponectin, leptin) and oxidative stress $\left(8 \text {-iso- } \mathrm{PGF}_{2 \alpha}\right)^{(27,28)}$. The postprandial studies only showed modest effects: higher endothelial cell function, decrease of sICAM-1 ${ }^{(29)}$ and reduced postprandial elevation of the IMA which is related to oxidative stress $^{(31)}$. In contrast, other three RCT administering daily doses of $1 \cdot 8 \mathrm{~g}, 0 \cdot 3 \mathrm{~g}$ and $0 \cdot 186 \mathrm{~g}$ of EPA + DHA showed significant reductions of CRP and of the inflammatory status ${ }^{(26,16,18)}$. Satoh et $a l^{(20)}$ also reported an increase in adiponectin, an anti-atherogenic adipocytokine, and reduced serum amyloid A-LDL complex, an oxidised form of LDL generated under inflammatory conditions. In the LIPGENE trials, the $n 3$ PUFA supplementation was carried out in the context of a low fat high complex carbohydrate diet, where other factors may play a role. The study by Benito et al. ${ }^{(16)}$ and Ebrahimi et $a l .{ }^{(18)}$ were poorly controlled and produced BP and body weight reductions. The only controlled study with weight stable MS patients in which both groups received the same diet showed CRP reductions in the $n 3$ supplemented group $^{(26)}$ but was performed with a low number of participants ( $n=44,22$ per group). More controlled studies with different doses of VLC $n 3$ PUFA and higher number of participants are necessary to test the effects of VLC $n 3$ PUFA on the inflammation associated with MS.

f) VLC $n-3$ PUFA and CHD risk. One study addressed this point ${ }^{(17)}$ by analysing the high TAG/low HDL-C subgroup of patients (administered with $1.8 \mathrm{~g} \mathrm{EPA} /$ day $+\mathrm{a}$ statin) of the JELIS primary prevention trial. The results showed that in the high TAG/low HDL-C group, the risk of major coronary events was particularly high, and EPA was shown to potently reduce the risk by $53 \%$. In the high TAG/low HDL-C group, level of plasma EPA at the time of registration was low, but EPA administration increased plasma levels, suggesting some correlation between plasma EPA level and major coronary events risk. Fish intake has been associated with decreased risk of $\mathrm{CVD}^{(70)}$. A few epidemiological studies have reported that men who ate at least some fish weekly had a lower coronary heart disease (CHD) mortality rate than that of men who ate none ${ }^{(59,71,72)}$. A 30-year follow-up of the Chicago Western Electric Study showed that men who consumed $35 \mathrm{~g}$ or more of fish daily compared with those who consumed 
none had a relative risk of death from CHD of 0.62 and a relative risk of nonsudden death from MI of $0.33^{(73)}$. For these reasons and on the basis of the available data, the regular intake of fish, at least twice a week (preferably oily fish), is recommended to patients without documented CHD like the MS patients.

\section{Concluding remarks}

MS is characterised by a cluster of CVD risk factors. The available RCT on MS patients convincingly show that the administration of VLC $n 3$ PUFA doses $>1 \mathrm{~g}$ for at least 3 months produced a significant reduction of triglycerides ranging from $7 \%$ to $25 \%$. These results confirm the hypotriglyceridemic effect of VLC $n 3$ PUFA in MS patients. The triglyceride lowering may produce further benefits on $\%$ sdLDL and perhaps ameliorate the inflammatory process associated with MS. No clear effects were found on other MS markers. High doses of VLC $n 3$ PUFA ( $\geq 3 \mathrm{~g}$ /day) may produce further TAG reductions but could raise other risk factors such as LDL-C. The combination of VLC $n 3$ PUFA plus a statin may be useful to prevent the occurrence of coronary events. More studies are needed using different amounts of VLC $n 3$ PUFA, time lengths, dietary backgrounds and different profiles of MS patients before clear recommendations can be made

Although both EPA and DHA are part of the fat composition of seafood products, their percentages in the oils differ depending on the species and other factors. Whilst fish oils in general usually contain about $30 \%$ of EPA + DHA, tuna oil can be as high as $25 \%$ in DHA and herring oil usually contains $18 \%$ of EPA. In recent years, differential effects on gene expression, cell function and physiology have been reported for EPA and DHA in their purified forms, reviewed in ${ }^{(74)}$. Indeed, purified EPA and DHA administered in capsules seem to have differential effects on serum lipids and lipoproteins, LDL particle size, glucose and insulin release ${ }^{(40,75)}$. In addition, DHA and EPA possess different affinity for organs. DHA generally exceeds EPA 5- to 30-fold in most organs ${ }^{(76)}$. Future research should explore these differential effects in MS patients. In addition, nutrigenetics and nutrigenomics are exceptional tools to identify possible EPA + DHA gene targets related to MS risk factors like obesity and insulin resistance.

Finally, in the last decade we have witnessed an extraordinary increase in the number of functional foods targeted to the ever-growing health conscious population. Several categories among these foods can be found according to their health target, including the cardiovascular (CV) system. These foods, when they are consumed regularly and in the context of a healthy diet and lifestyle, intend to maintain or improve the CV health by reducing the levels of risk factors. The dietary supplementation of MS patients with EPA + DHA produces benefits. Apart from increasing the intake of fish, the use of functional foods enriched with EPA + DHA represents an alternative that may produce benefits in MS patients ${ }^{(16,77)}$.

\section{Conflict of interest}

The author declares no conflict of interest.

\section{Acknowledgements}

This research received no specific grant from any funding agency in the public, commercial or not-for-profit sectors. The author would like to express his gratitude to Prof Carmina Wanden-Berghe of Cardenal Herrera University of Elche (Spain) and Prof Angel Gil of Granada University (Spain) for their guidance and help with the article search and screening of abstracts. The author would also like to thank Juan J Carrero of the Karolinska Institut at Stockholm (Sweden), for his help with the publication.

\section{References}

1. Expert Panel (2001) Executive summary of the third report of the National Cholesterol Education Program Expert Panel on Detection, Evaluation, and Treatment of High Blood Cholesterol in Adults (Adult Treatment Panel III). JAMA 285, 2486-2497.

2. Zimmet P, Alberti KG, Shaw J, et al. (2001) Global and societal implications of the diabetes epidemic. Nature $\mathbf{4 1 4}$, $782-787$.

3. Eckel RH, Grundy SM \& Zimmet PZ (2005) The metabolic syndrome. Lancet 365, 1415-1428.

4. Grundy SM, Cleeman JI, Daniels SR, et al. (2005) Diagnosis and management of the metabolic syndrome. An American Heart Association/National Heart, Lung, and Blood Institute scientific statement. Circulation 112, 2735-2752.

5. Roche HM (2005) Fatty acids and the metabolic syndrome. Proc Nutr Soc 64, 23-29.

6. Melanson EL, Astrup A \& Donahoo WT (2009) The relationship between dietary fat and fatty acid intake and body weight, diabetes, and the metabolic syndrome. Ann Nutr Metab 55, 229-243.

7. Warensjo E, Riserus U \& Vessby B (2005) Fatty acid composition of serum lipids predicts the development of the metabolic syndrome in men. Diabetologia 48, 1999-2005.

8. Hooper L, Thompson RL, Harrison RA \& SummerbellOmega 3 fatty acids for prevention and treatment of cardiovascular disease (Cochrane Review) In: The Cochrane Library, Issue 2. Oxford, update 1 August 2004

9. EFSA (2009) Opinion of the scientific panel on dietetic products, nutrition and allergies on a request from the Commission related to labelling reference intake values for n-3 and $n-6$ polyunsaturated fatty acids. EFSA J 1176, 1-11.

10. FAO/WHO (2010) The Joint FAO/WHO Expert Consultation on Fats and Fatty Acids in Human Nutrition. FAO food and nutrition paper 91. Food and Agriculture Organisation of the United Nations, Rome. ISSN 0254-4725.

11. Kris-Etherton PM, Harris WS, Appel LJ \& AHA Nutrition Committee, American Heart Association (2003) Omega-3 fatty acids and cardiovascular disease: new recommendations from the American Heart Association. Arterioscler Thromb Vasc Biol 23, 151-152.

12. Yamada H, Yoshida M, Nakano, et al. (2008) In vivo and in vitro inhibition of monocyte adhesion to endothelial cells and endothelial adhesion molecules by eicosapentaenoic acid. Arterioscler Thromb Vasc Biol 28, 2173-2179.

13. Esposito K, Marfella R, Ciotola M, et al. (2004) Effect of a mediterranean-style diet on endothelial dysfunction and markers of vascular inflammation in the metabolic syndrome: a randomized trial. JAMA 292, 1440-1446.

14. Shaw DI, Tierney AC, McCarthy S, et al. (2009) LIPGENE food-exchange model for alteration of dietary fat quantity 
and quality in free-living participants from eight European countries. Br J Nutr 101, 750-759.

15. Brady LM, Williams CM \& Lovegrove JA (2004) Dietary PUFA and the metabolic syndrome in Indian Asians living in the UK. Proc Nutr Soc 63, 115-125.

16. Benito P, Caballero J, Moreno J, et al. (2006) Effects of milk enriched with omega-3 fatty acid, oleic acid and folic acid in patients with metabolic syndrome. Clin Nutr 25, 581-587.

17. Saito Y, Yokoyama M, Origasa H, JELIS Investigators Japan, et al. (2008) Effects of EPA on coronary artery disease in hypercholesterolemic patients with multiple risk factors: sub-analysis of primary prevention cases from the Japan EPA Lipid Intervention Study (JELIS). Atherosclerosis 200, 135-140.

18. Ebrahimi M, Ghayour-Mobarhan M \& Rezaiean S (2009) Omega-3 fatty acid supplements improve the cardiovascular risk profile of subjects with metabolic syndrome, including markers of inflammation and auto-immunity. Acta Cardiol 64, 321-327.

19. Tulk HM \& Robinson LE (2009) Modifying the $n-6 / n-3$ polyunsaturated fatty acid ratio of a high-saturated fat challenge does not acutely attenuate postprandial changes in inflammatory markers in men with metabolic syndrome. Metabolism 58, 1709-1716.

20. Satoh N, Shimatsu A \& Kotani K (2009) Highly purified eicosapentaenoic acid reduces cardio-ankle vascular index in association with decreased serum amyloid A-LDL in metabolic syndrome. Hypertens Res 32, 1004-1008.

21. Montegaard C, Tulk HM \& Lauritzen L (2010) Acute ingestion of long-chain (n-3) polyunsaturated fatty acids decreases fibrinolysis in men with metabolic syndrome. J Nutr 140 , $38-43$.

22. Hartwich J, Malec MM \& Partyka L (2009) The effect of the plasma n-3/n-6 polyunsaturated fatty acid ratio on the dietary LDL phenotype transformation - insights from the LIPGENE study. Clin Nutr 28, 510-515.

23. Jiménez-Gómez Y, Marín C, Pérez-Martínez P, et al. (2010) A low-fat, high-complex carbohydrate diet supplemented with long-chain (n-3) fatty acids alters the postprandial lipoprotein profile in patients with metabolic syndrome. J Nutr 140, 1595-1601.

24. Gulseth HL, Gjelstad IM, Tierney AC, et al. (2010) Dietary fat modifications and blood pressure in subjects with the metabolic syndrome in the LIPGENE dietary intervention study. Br J Nutr 104, 160-163.

25. Simão AN, Godeny P \& Lozovoy MA (2010) Effect of n-3 fatty acids in glycemic and lipid profiles, oxidative stress and total antioxidant capacity in patients with the metabolic syndrome. Arq Bras Endocrinol Metabol 54, 463-469.

26. Satoh N, Shimatsu A, Kotani K, et al. (2007) Purified eicosapentaenoic acid reduces small dense LDL, remnant lipoprotein particles, and C-reactive protein in metabolic syndrome. Diabetes Care 30, 144-146.

27. Tierney AC, McMonagle J, Shaw DI, et al. (2010) Effects of dietary fat modification on insulin sensitivity and on other risk factors of the metabolic syndrome-LIPGENE: a European randomized dietary intervention study. Int J Obes (Lond) (Epublication 12 October 2010 ahead of print version).

28. Petersson H, Risérus U, McMonagle J, et al. (2010) Effects of dietary fat modification on oxidative stress and inflammatory markers in the LIPGENE study. Br J Nutr 104, 1357-1362.

29. Perez-Martinez P, Moreno-Conde M, Cruz-Teno C, et al. (2010) Dietary fat differentially influences regulatory endothelial function during the postprandial state in patients with metabolic syndrome: from the LIPGENE study. Atherosclerosis 209, 533-538.
30. van Hees AM, Saris WH, Hul GB, et al. (2010) Effects of dietary fat modification on skeletal muscle fatty acid handling in the metabolic syndrome. Int J Obes (Lond) $\mathbf{3 4}$, $859-870$

31. Hartwich J, Leszczynska-Golabek I, Kiec-Wilk B, et al. (2010) Lipoprotein profile, plasma ischemia modified albumin and LDL density change in the course of postprandial lipemia. Insights from the LIPGENE study. Scand J Clin Lab Invest 70, 201-208.

32. Balk EM, Lichtenstein AH, Chung M, Kupelnick B, Chew P \& Lau J (2006) Effects of omega-3 fatty acids on serum markers of cardiovascular disease risk: a systematic review. Atherosclerosis 189, 19-30.

33. Vessby B, Unsitupa M, Hermansen K, et al. (2001) Substituting dietary saturated for monounsaturated fat impairs insulin sensitivity in healthy men and women: The KANWU Study. Diabetologia 44, 312-319.

34. Masson D, Jiang XC, Lagrost L \& Tall AR (2009) The role of plasma lipid transfer proteins in lipoprotein metabolism and atherogenesis. J Lipid Res, Supp. 1, S201-S206.

35. Ministry of Health, Labour and Welfare. The National Nutrition Survey in Japan (2001) Health and Nutrition Information Research Committee, eds. Tokyo, Japan: Daiichi Shuppan; 2003: 83-91.

36. Pockley AG, Georgiades A, Thulin T, et al. (2003) Serum heat shock protein 70 levels predict the development of atherosclerosis in subjects with established hypertension. Hypertension 42, 235-238.

37. Ogasawara K, Mashiba S, Wada Y, et al. (2004) A serum amyloid A and LDL complex as a new prognostic marker in stable coronary artery disease. Atherosclerosis 174, 349-356.

38. Matsuzawa Y, Funahashi T, Kihara S, et al. (2004) Adiponectin and metabolic syndrome. Arterioscler Thromb Vasc Biol 24, 29-33.

39. Mansia G, De Backer G, Dominiczak A, et al. (2007) Guidelines for the management of arterial hypertension: the task force for the management of arterial hypertension of the European Society of Hypertension (ESH) and of the European Society of Cardiology (ESC). J Hypertens 25, 1105-1187.

40. Mori TA, Burke V, Puddey IB, et al. (2000) Purified eicosapentaenoic and docosahexaenoic acids have differential effects on serum lipids and lipoproteins, LDL particle size, glucose, and insulin in mildly hyperlipidemic men. Am J Clin Nutr 71, 1085-1094.

41. Woodman RJ, Mori TA, Burke V, et al. (2002) Effects of purified eicosapentaenoic and docosahexaenoic acids on glycemic control, blood pressure, and serum lipids in type 2 diabetic patients with treated hypertension. Am J Clin Nutr 76, 1007-1015.

42. Zilversmit DB (1979) Atherogenesis: a postprandial phenomenon. Circulation 60, 473-485.

43. Kolovou GD, Anagnostopoulou KK, Daskalopoulou SS, et al. (2005) Clinical relevance of postprandial lipaemia. Curr Med Chem 12, 1931-1945.

44. Ruotolo G \& Howard BV (2002) Dyslipidemia of the metabolic syndrome. Curr Cardiol Rep 4, 494-500.

45. Giugliano D, Ceriello A \& Esposito K (2008) Are there specific treatments for the metabolic syndrome? Am J Clin Nutr 87, 8-11.

46. Harris WS (2007) Omega-3 fatty acids and cardiovascular disease: a case for omega-3 index as a new risk factor. Pharmacol Res 55, 217-223.

47. The British Nutrition Foundation (1999) n-3 Fatty Acids and Health. Briefing Paper. London: British Nutrition Foundation. 
48. Baro L, Fonollá J, Peña JL, et al. (2003) n-3 Fatty acids plus oleic acid and vitamin supplemented milk consumption reduces total and LDL cholesterol, homocysteine and levels of endothelial adhesion molecules in healthy humans. Clin Nutr 22, 175-182.

49. Carrero JJ, Baró L, Fonollá J, et al. (2004) Cardiovascular effects of milk enriched with o-3 polyunsaturated fatty acids, oleic acid, folic acid, and vitamins $\mathrm{E}$ and B6 in volunteers with mild hyperlipidemia. Nutrition 20, 521-527.

50. Jacobsen TA (2008) Role of n-3 fatty acids in the treatment of hypertriglyceridemia and cardiovascular disease. Am J Clin Nutr 87, 1981S-1990S

51. Harris WS (1997) n-3 Fatty acids and serum lipoproteins: Human studies. Am J Clin Nutr 65, 1645-1654.

52. EFSA Panel on Dietetic Products, Nutrition and Allergies (2009) Scientific Opinion on the substantiation of health claims related to EPA, DHA, DPA and maintenance of normal blood pressure (ID 502), maintenance of normal HDL-cholesterol concentrations (ID 515), maintenance of normal (fasting) blood concentrations of triglycerides (ID 517), maintenance of normal LDL-cholesterol concentrations (ID 528, 698) and maintenance of joints (ID 503, 505, 507, $511,518,524,526,535,537)$ pursuant to Article 13(1) of Regulation (EC) No 1924/2006. EFSA J 7, 1263-1289.

53. Austin MA, Breslow JL \& Hennekens CH (1988) Low density lipoprotein subclass patterns and risk of myocardial infarction. JAMA 260, 1917-1921.

54. Rizzo M \& Berneis K (2006) Low density lipoproteins size and cardiovascular risk assessment. QJM 99, 1-14.

55. Kwiterovich PO Jr (2002) Clinical relevance of the biochemical, metabolic, and genetic factors that influence low-density lipoprotein heterogeneity. Am J Cardiol 90, 30i-47i.

56. Griffin BA (1999) Lipoprotein atherogenicity: an overview of current mechanisms. Proc Nutr Soc 58, 163-169.

57. Murphy KJ, Meyer BJ, Mori TA, et al. (2007) Impact of foods enriched with $n-3$ long-chain polyunsaturated fatty acids on erythrocyte n-3 levels and cardiovascular risk factors. $\mathrm{Br} \mathrm{J}$ Nutr 97, 749-757.

58. Mancia G, De Backer G, Dominiczak A, et al. (2007) Management of Arterial Hypertension of the European Society of Hypertension; European Society of Cardiology, 2007. 2007 Guidelines for the Management of Arterial Hypertension: The Task Force for the Management of Arterial Hypertension of the European Society of Hypertension (ESH) and of the European Society of Cardiology (ESC). J Hypertens 25, 1105-1187.

59. Kromhout D, Bosschieter EB \& de Lezenne Coulander C (1985) The inverse relation between fish consumption and 20-year mortality from coronary heart disease. $N$ Engl J Med 312, 1205-1209.

60. Galgani JE, Uauy RD, Aguirre CA, et al. (2008) Effect of the dietary fat quality on insulin sensitivity. Br J Nutr 100, 471-479.

61. Nettleton JA \& Katz R (2005) n-3 long-chain polyunsaturated fatty acids in type 2 diabetes: a review. J Am Diet Assoc 105, $428-440$
62. Friedberg CE, Janssen MJ, Heine RJ, et al. (1998) Fish oil and glycemic control in diabetes. A meta-analysis. Diabetes Care 21, 494-500.

63. Montori VM, Farmer A, Wollan PC, et al. (2000) Fish oil supplementation in type 2 diabetes: a quantitative systematic review. Diabetes Care 23, 1407-1415.

64. Hartweg J, Perera R, Montori V, et al. (2008) Omega-3 polyunsaturated fatty acids (PUFA) for type 2 diabetes mellitus. Cochrane Database Syst Rev CD003205.

65. Hartweg J, Farmer AJ, Holman RR, et al. (2009) Potential impact of omega-3 treatment on cardiovascular disease in type 2 diabetes. Curr Opin Lipidol 20, 30-38.

66. Mostad IL, Bjerve KS, Basu S, et al. (2009) Addition of n-3 fatty acids to a 4-hour lipid infusion does not affect insulin sensitivity, insulin secretion, or markers of oxidative stress in subjects with type 2 diabetes mellitus. Metabolism $\mathbf{5 8}$, $1753-1761$.

67. Pickup JC (2004) Inflammation and activated innate immunity in the pathogenesis of type 2 diabetes. Diabetes Care 27, 813-823.

68. Basu S (2007) Novel cyclooxygenase-catalyzed bioactive prostaglandin F2alpha from physiology to new principles in inflammation. Med Res Rev 27, 435-468.

69. Basu S (2008) F2-isoprostanes in human health and diseases: from molecular mechanisms to clinical implications. Antioxid Redox Signal 10, 1405-1434.

70. Kris-Etherton PM, Harris WS, Appel LJ \& American Heart Association. Nutrition Committee (2002) Fish consumption, fish oil, omega-3 fatty acids, and cardiovascular disease. Circulation 106, 2747-2757.

71. Kromhout D, Feskens EJ \& Bowles CH (1995) The protective effect of a small amount of fish on coronary heart disease mortality in an elderly population. Int J Epidemiol 24, 340-345.

72. Dolecek TA \& Granditis G (1991) Dietary polyunsaturated fatty acids and mortality in the Multiple Risk Factor Intervention Trial (MRFIT). World Rev Nutr Diet 66, 205-216.

73. Daviglus ML, Stamler J, Orencia AJ, et al. (1997) Fish consumption and the 30-year risk of fatal myocardial infarction. $N$ Engl J Med 336, 1046-1053.

74. Gorjão R, Azevedo-Martins AK, Rodrigues HG, et al. (2009) Comparative effects of DHA and EPA on cell function. Pharmacol Ther 122, 56-64.

75. Buckley R, Shewring B, Turner R, et al. (2004) Circulating triacylglycerol and apoE levels in response to EPA and docosahexaenoic acid supplementation in adult human subjects. Br J Nutr 92, 477-483.

76. Arterburn LM, Hall EB \& Oken H (2006) Distribution, interconversion, and dose response of n-3 fatty acids in humans. Am J Clin Nutr 83, 1467S-1476S.

77. Lopez-Huertas E (2010) Health effects of oleic acid and long chain omega-3 fatty acids (EPA and DHA) enriched milks. A review of intervention studies. Pharmacol Res $\mathbf{6 1}$, 200-207. 